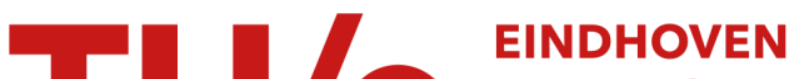 \\ UNIVERSITY OF \\ TECHNOLOGY
}

\section{Thermal stratification in heat storages}

Citation for published version (APA):

Veltkamp, W. B. (1981). Thermal stratification in heat storages. In C. Ouden, den (Ed.), Thermal storage of solar energy : proceedings of an international TNO-symposium, 5-6 November 1980, Amsterdam (pp. 47-59). Nijhoff.

Document status and date:

Published: 01/01/1981

\section{Document Version:}

Publisher's PDF, also known as Version of Record (includes final page, issue and volume numbers)

\section{Please check the document version of this publication:}

- A submitted manuscript is the version of the article upon submission and before peer-review. There can be important differences between the submitted version and the official published version of record. People interested in the research are advised to contact the author for the final version of the publication, or visit the $\mathrm{DOI}$ to the publisher's website.

- The final author version and the galley proof are versions of the publication after peer review.

- The final published version features the final layout of the paper including the volume, issue and page numbers.

Link to publication

\section{General rights}

Copyright and moral rights for the publications made accessible in the public portal are retained by the authors and/or other copyright owners and it is a condition of accessing publications that users recognise and abide by the legal requirements associated with these rights.

- Users may download and print one copy of any publication from the public portal for the purpose of private study or research.

- You may not further distribute the material or use it for any profit-making activity or commercial gain

- You may freely distribute the URL identifying the publication in the public portal.

If the publication is distributed under the terms of Article 25fa of the Dutch Copyright Act, indicated by the "Taverne" license above, please follow below link for the End User Agreement:

www.tue.nl/taverne

Take down policy

If you believe that this document breaches copyright please contact us at:

openaccess@tue.nl

providing details and we will investigate your claim. 
THERMAL STRATIFICATION IN HEAT STORAGES.

W.B. VELTKAMP

1. INTRODUCTION

The term "thermal stratification" suggests a discontinuous temperaturefield. Though such is impossible the term corresponds well with our image of the phenomenon. In general we understand by thermal stratification a non scalar temperaturefield, - more particular in a fluid medium, - which is an increasing function of only the elevation. In a solar energy system, thermally stratified storing leads to a considerable increase in solar heat and a reduction of pumping energy. In some multipurpose installations stratification may also have the

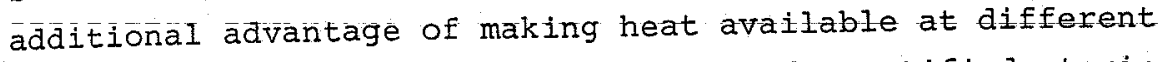
temperatures. Although the advantages of stratified storing have been noticed in the early days of solar development, they are still grossly underestimated in almost all literature and handbooks. The reasons for this state of affairs have been indicated by van Koppen e.a. $|1|$. Following their lines of thought further progress in establishing a better design method for solar systems and storing has been made at the Eindhoven University of Technology. This paper is mainly concerned with some of the conclusions that have been reached in this research. The main objective of the paper is to demonstrate that these conclusions hold for actual systems.

\section{ANALYSIS}

A perfect solar system would encompass such unattainable features as infinitely large heat exchangers operating in counterflow and incurring no temperature drop, a stratified storage without any mixing or heatconduction, fully absorbing collector 
plate coatings and so on. It may seem futile to enter upon the analysis of such perfect systems as economics will certainly make their realisation impossible. Yet, assuming all features in a system but a few as ideal sometimes leads to a simpler analysis of the system, and consequently to a better insight in the factors that determine the output of a solar system and the objectives that are to be selected for research and development. This is, according to the experience at the EUT, certainly true for the analysis of the role which stratified storing can play in improving the output of solar systems. However in this paper I shall only follow this approach with regard to the options to establish thermal stratification in the storage. Instead of a perfect system I shall present some of the results we have obtained by means of careful measurements and a well validated model of the solar heating and hot water system of the laboratories of the Food Inspection Department at Enschede, the Netherlands. In this way I hope to demonstrate: - that thermally stratified storing can enhance the output of a real system by $20 \%$ or more,

- that to this end the mass flow rate through the collector has to be reduced to about a third of the commonly used value, - that in order to reach this result the average heat capacity flow through the collector has to be related to, and in general slightly higher, than the heat capacity flow through the distribution circuits, and

- that a thermally well stratified storage can practically be realised in various ways.

The third aspect is one of the features that has been analysed in more detail in the EUT laboratories. A relation between this "average equality" and the heat capacity of the storage has also been established in our work, and will be the basis of the next paper by Professor Rademaker. A further account of other topics of our work will be given in some papers that are currently prepared for professional periodicals.

3. MODELLING A STRATIFIED STORAGE

The model of a stratified storage that we have developed is 
of a fairly general nature and can be used for most of the system configurations commonly used, both for liquids and solid storage materials. The most important simplification in the model is the one-dimensionality, i.e. the temperature depends on only one space direction. If for any reason a temperature inversion is introduced in a fluid storage, the behaviour is described as an instantly mixing of the adjacent layers, with complete temperature equalisation. The discretisation of the storage is in a number of segments with fixed positions. Contrary to the usual statements in the literature, the convergence of such a model proved to be slow, namely linear with the place discretisation, i.e. the error is inversely proportional to the number of segments. Further the error in the final result appeared to be proportional to the heat loss factor of the collector. E.g. a loss factor of $6 \mathrm{Wm}^{-2} \mathrm{~K}^{-1}$, a discretisation of the storage in 16 segments and a sequentialisation in steps of 5 minutes leads to an error in the yearly energy output of about $1.5 \%$ and an error in the collector throughput of about 5\%. The error is an underestimation compared to reality. In this context it should be noted that the investigations reported in the open literature on the benefits of stratification are mostly carried out with a discretisation in only 3 segments. Our systematic investigations have shown that as a consequence the output of the solar system is underestimated by as much as $10 \%$

\section{MEASUREMENTS AND VALIDATION OF THE STRATIFIED STORAGE MODEL}

In the Netherlands the solar heating and hot water projects in Eindhoven (Solar House of the EUT) and in Enschede (Laboratory of the Food Inspection Department) have, from the very start, been designed to take full advantage of the stratification. Therefore floating inlets are applied in the water storages in both systems. The system configuration in Enschede (see Fig. 1) is notable by the two floating inlets, one for the return of the collector and one for the return of the heating system. By means of the last inlet (left in Fig. 1) it was possibie to introduce a temperature inversion in the storage and so to observe and analyse the behaviour with locally disturbed 


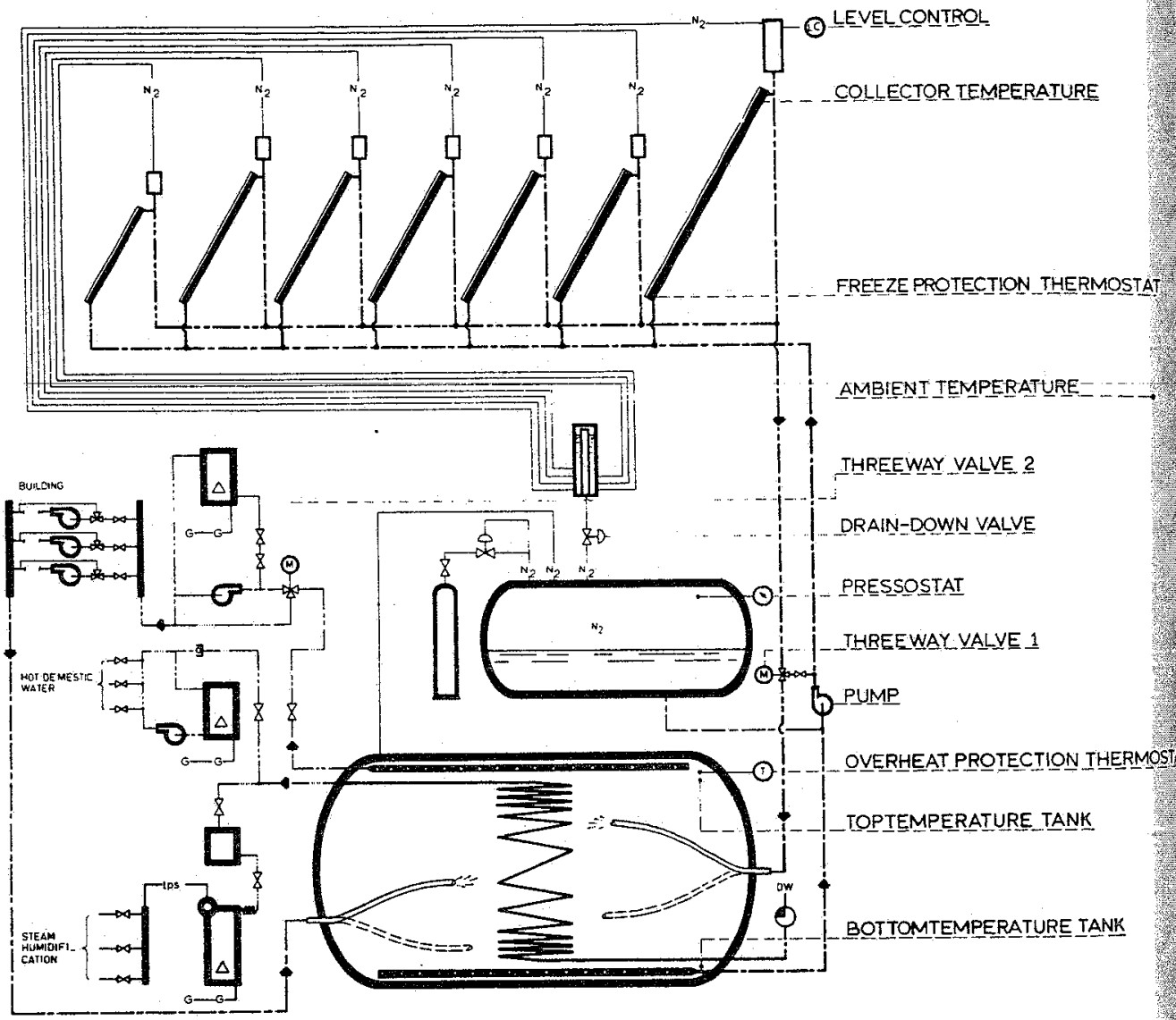

FIGURE 1. Schematic of the installation at Enschede (collector area $344 \mathrm{~m}^{2}$, storage volume $31 \mathrm{~m}^{3}$, working fluid demineralised water).

stratification. In order to introduce the disturbance the flow through the (air) heating system was set at maximum, thereby bringing the hot water from the top of the storage to the ultimate reach of the floating inlet, which is about halfway up the tank. Figure 2 permits a judgement of the quality of the stratified storage and system model that has been developed. The curves cover a three day period (29-31 aug. 1979) during which the storage was heated via the collectors during the day and its upper half was "inverted" via the heating circuit during the night. Moreover hot water was used during daytimes, and also some heating was applied, resulting in a really complex 


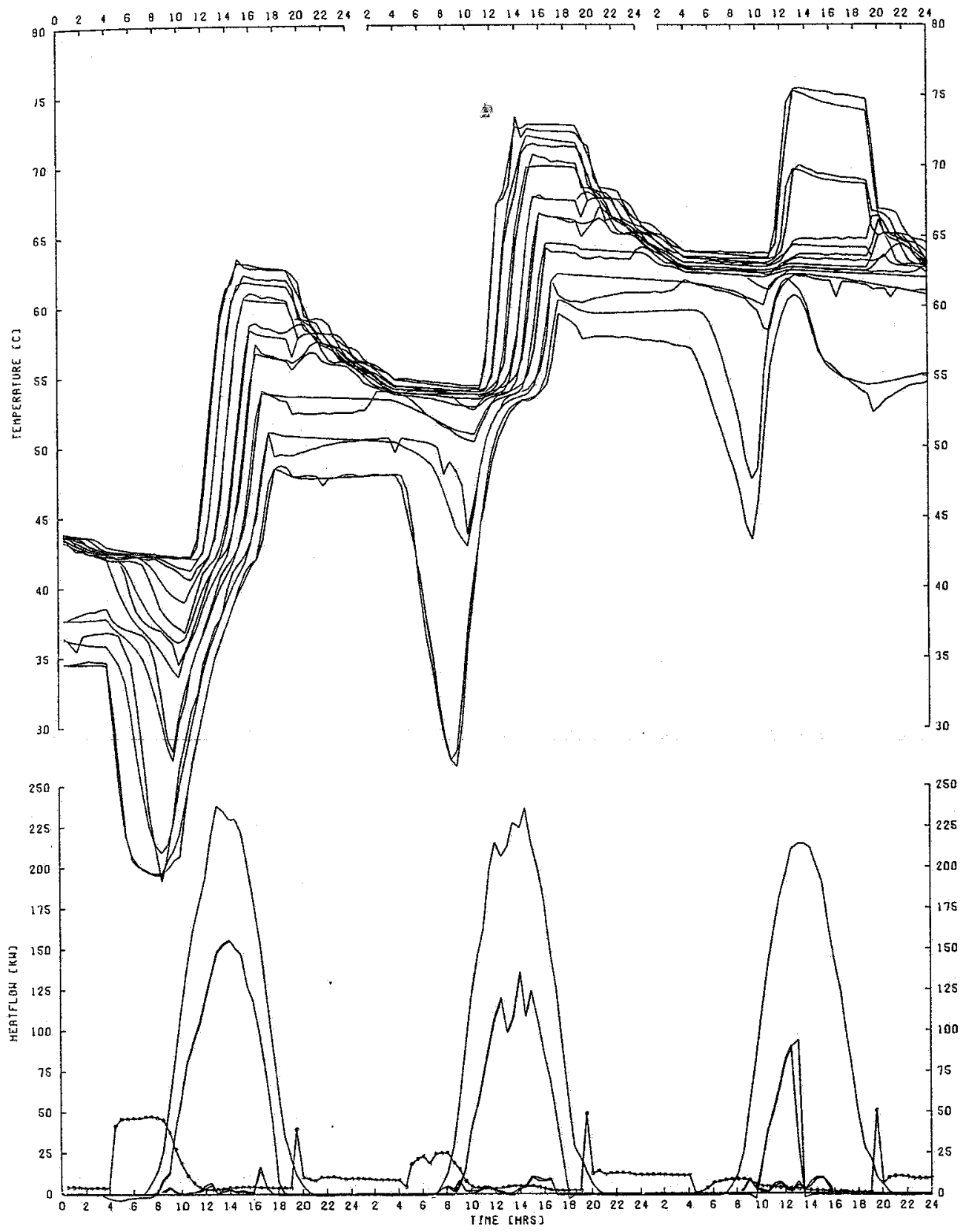

FIGURE 2. Measurements and simulation of the Enschede system during 3 days (29-31 Aug., 1979). Light lines represent measurement heavy lines simulation. Upper part: 8 storage temperatures for subsequent segments of equal volume. Lower part: higher curve = incident irradiation, second curve = heat flow from collector, dotted curve $=$ load of heating system, lower curve $=$ hot service water load. 
supply and demand pattern. The curves in Fig. 2 - both the experimental and calculated - show how the stratification is established during the day (only in the upper half of the tank on the third day because the overheating protection acts) and how the upper part of the storage is gradually mixed during the "inversion period" at night. It should be noted that the slopes of the curves represent the speed at which the water in the storage moves up or down. Parallel curves indicate the absence of mixing, whereas curves approaching each other demonstrate mixing and parting curves indicate the presence of a floating inlet.

The agreement between the experimental and calculated curves is as good as can be expected under the complex load and supply pattern investigated. Important however is the experience that this agreement could only be reached with a division of the storage in 64 segments. A smaller number inevitable led to deviations, particularly as regards the slopes of the temperature curves, the cause being an artificial heat conduction connected with the transport of water across the boundaries of the segments. The penalty for this good agreement in terms of computing time is considerable, For instance a year's run with only 16 segments, hourly weather data and 5 minutes time steps already takes a procestime of about $200 \mathrm{sec}$ on a fast Burroughs 7600. Even then the performance is still underestimated by $1.5 \%$ for a collector heat loss factor of $6 \mathrm{Wm}^{-2} \mathrm{~K}^{-1}$, as mentioned before.

\section{THE OPTIMUM COLLECTORFLOW}

As Rademaker $|2|$ and van koppen e.a.|1| have shown an optimum non infinite collectorflow exists for a solar system with a stratified storage (here we consider only on-off control and fixed flow).

With the validated model, the dependence of the energy gain on the collectorflow is now analysed for the Enschede system for the actual configuration and some modifications. These modifications were selected with the objective to disclose: - the benefits of stratification as compared to uniform storage, 
- the performance difference between a floating inlet and three other simple means of obtaining stratification, namely an amply dimensioned heat exchanging coil, supplying the water from the collectors in the top of the tank and storing the heat in some porous medium (e.g. a pebble bed or soil),

- the influence of the quality of the collector, by substituting $\mathrm{U}_{\mathrm{I}}=1.8 \mathrm{Wm}^{-2} \mathrm{~K}^{-1}$ and $\alpha \tau=.67$ in place of the actually measured $U_{L}^{I}=6.2 \mathrm{Wm}^{-2} \mathrm{~K}^{-1}$ and $\alpha \tau=.76$ and

- the usefulness of the second floating inlet for the heating system.

The calculations were made with the Dutch reference year developed by the EUT $|3|$, as hourly-climatic input. The heating load of the laboratory was determined by means of the repeatedly validated computerprogram KLI $|4|$, with timesteps of 5 minutes to preserve any dynamic effects, the annual heating load amounted to $124 \mathrm{MWh}$. The hot water load was assumed to be evenly distributed over the working hours and to total up to an annual $70 \mathrm{MWh}$. In this way a close approximation to reality was attained, the most important deviation probably being that the disçretisation of the storage wàs restericted by 16 segments in order to save computing time. As mentioned before this leads to an underestimation of the heat gain of $1.5 \%$ for the conventional spectral selective, collector and of .5\% for the vacuum collector. In fig. 3 the useful heat gains calculated are depicted versus the collector flow rate per unit of collector area. The upper group of curves concerns the vacuum collector, the lower group the actual, conventional collector. From the results the following conclusions can be drawn:

- in both groups all the systems with a stratified storage exhibit a maximum heat gain at the low collectorflow rate of about $.012 \mathrm{~m}^{3} \mathrm{~m}^{-2} \mathrm{hr}^{-1}$. In all cases this maximum is higher than the best output obtained with a uniform storage at an infinite flow rate. The best stratified system (with floating inlets) shows an extra heat gain of $7 \%$ for the vacuum collectors and of as much as $19 \%$ for the conventional collectors,

- replacing the collector's floating inlet by a heat exchanging coil or an inlet in the top of the tank reduces the heat gain 


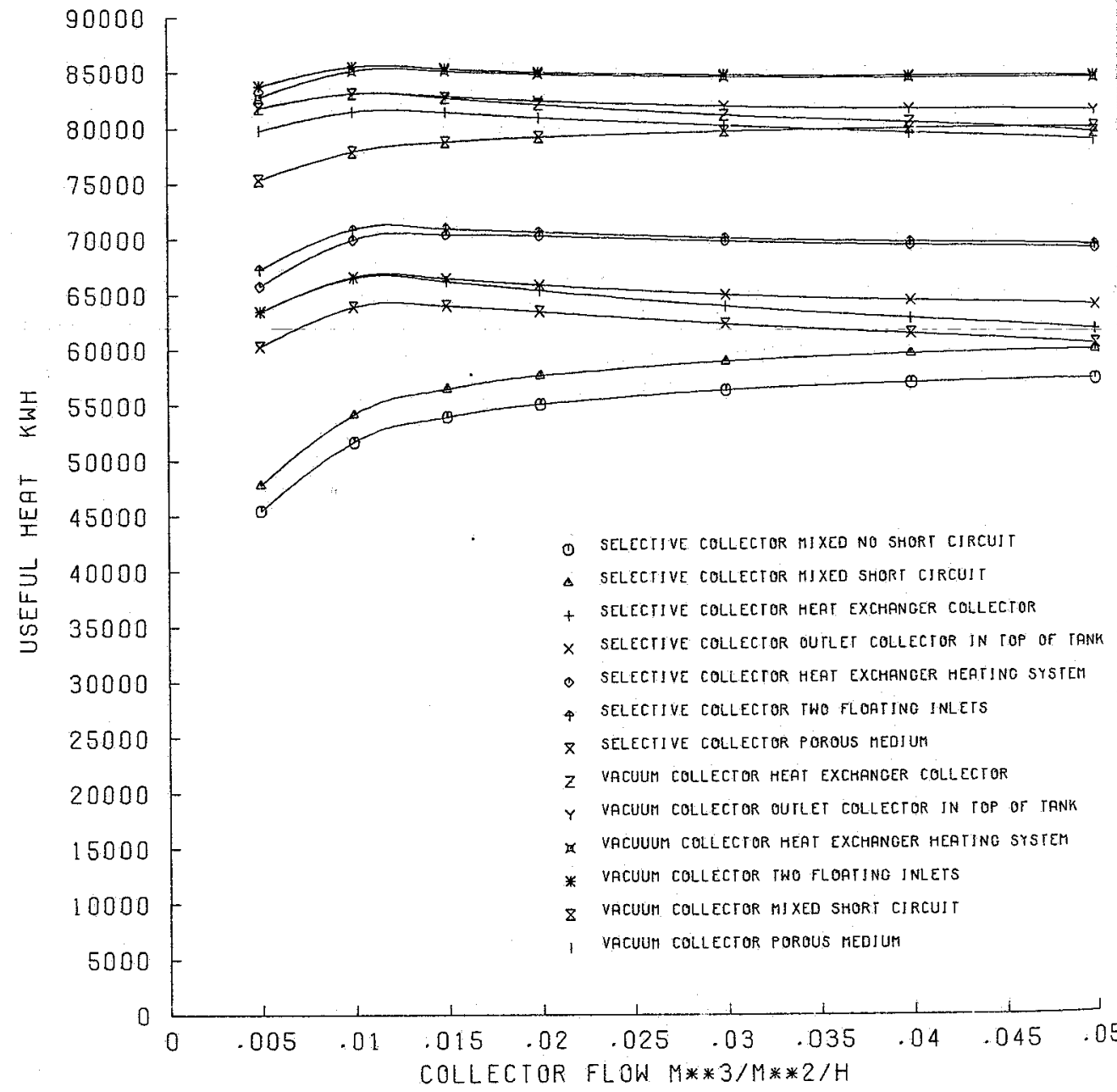

FIGURE 3. The useful heat versus the collectorflow, for several system configurations and two collectortypes.

by $3 \%$ for the vacuum- and by $7 \%$ for the conventional collectors, - storing in a porous (say solid) medium leads to a $5 \%$ lower heat gain for the vacuum collectors and a $11 \%$ lower heat gain for the conventional collectors, again compared with the floating inlet system,

- if no floating inlet for the collector is applied, the stratified and uniform storages converge to the same value as the flow goes to infinity. Contrary this convergency does not excist for a system with a floating inlet for the collector. 
- in the best stratified system the vacuum collectors perform $20 \%$ better than the conventional ones; for the uniform storage the difference amounts to as much as $32 \%$. As expected the vacuum collector systems are less sensitive to the quality of the other components of the installation than the systems with the conventional collectors. The sensitivity seems to be roughly proportional to $U_{L}$, which is not surprising as the heat losses of the collectors are proportional to $U_{\mathrm{L}^{\prime}}$,

- finally, replacing the heating system's floating inlet by an ample dimensioned heat exchanging coil leads to minor reductions in performance, accounting to .4\% for the vacuum collector and $1 \%$ for the conventional collectors.

Although calculated for the Enschede system these results are in the opinion of the author typical for the majority of the heating and/or hot water systems in a humid, meso thermal marine climate, like the Dutch. There is also little reason why they would be essentially different for other climates or for systems with a seasonal storage as long as the stratification is maintained.

From an energy conservation point of view the comparison just presented is incomplete as the pumping energy has to be taken into account when determining the energy displaced. However the pumping energy strongly depends on the layout of the installation and no general conclusions can be drawn from results determined for a particular system! Therefore we have chosen to take into account a fairly low pumping energy of $.4 \mathrm{wm}^{-2}$ at a flow rate of $.015 \mathrm{~m}^{3} \mathrm{~m}^{-2} \mathrm{hr}^{-1}$. Further the pumping energy was assumed to be proportional to the flow rate to the power $7 / 4$, and the ratio between primary and electric energy to be equal to 3 . Figure 4 shows the so calculated displaced energies. As expected the optimum collectorflow rate shifts to a somewhat lower value, the optima are more pronounced and the curves for a uniform storage now show a maximum at a finite collector flow rate. In table I some absolute and relative numerical results for the displaced energy are presented; they permit a comparison between the various system configurations. Obviously the pumping energy does hardy change the optimum value of the flow rate. 


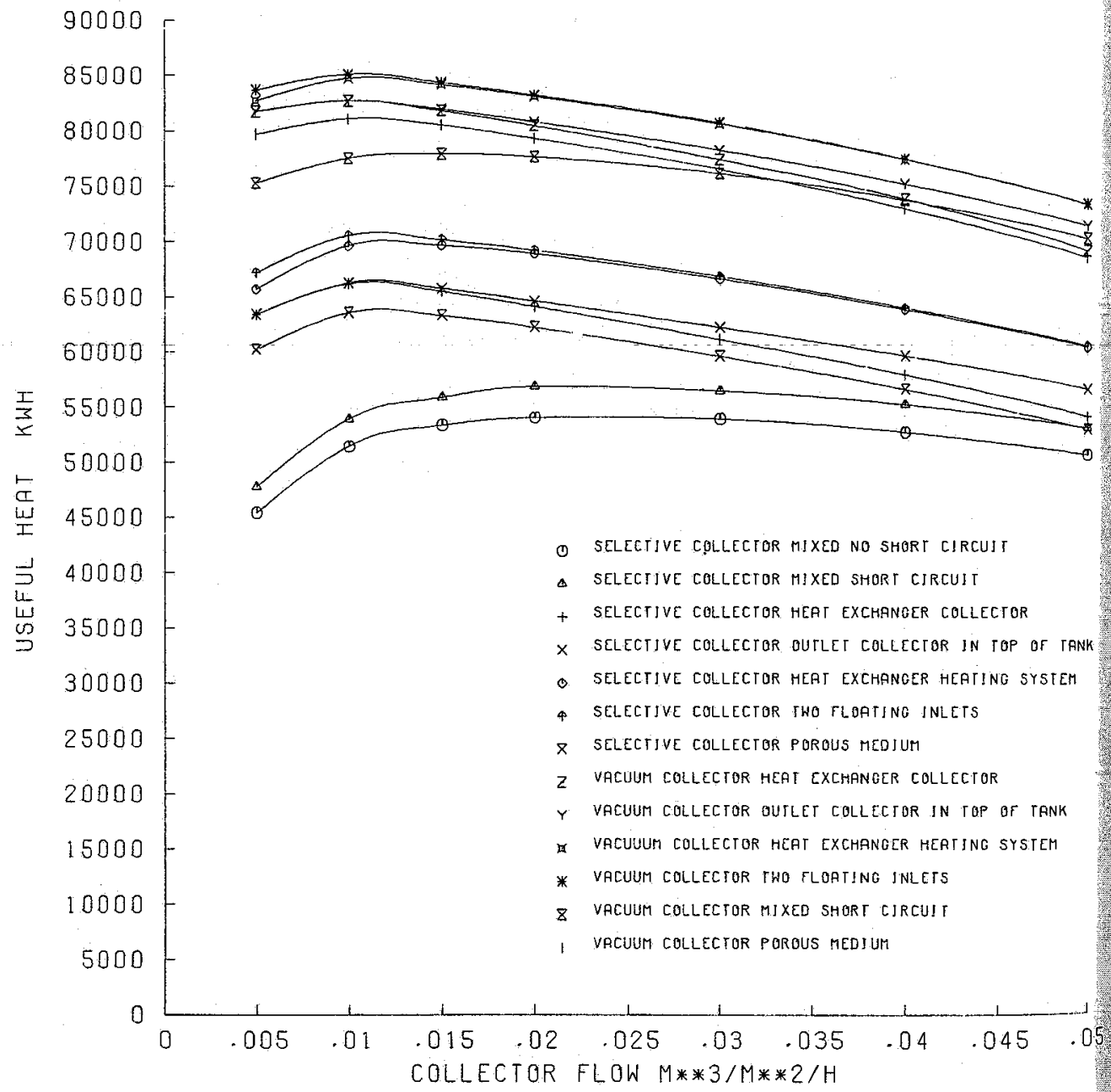

FIGURE 4. The displaced primary energy versus the collectorflow for a pumping energy of $.4 \mathrm{Wm}^{-2}$ at a flow rate of $.015 \mathrm{~m}^{3} \mathrm{~m}^{-2} \mathrm{hr}^{-1}$ for several system configurations and two collectortypes.

\begin{tabular}{|c|c|c|c|c|c|c|c|}
\hline \multirow{2}{*}{\multicolumn{2}{|c|}{$\underline{S}$}} & \multicolumn{3}{|c|}{ Conv. $\operatorname{col} 1 . \mathrm{U}_{\mathrm{I}}=6.2 \mathrm{Wm}^{-2} \mathrm{~K}^{-1}$} & \multicolumn{3}{|c|}{$\mathrm{Vac} . \operatorname{col} 1: \mathrm{U}_{\mathrm{L}}=1.8 \mathrm{Wm}^{-2} \mathrm{~K}$} \\
\hline & & $\mathrm{kWh} / \mathrm{Yr}$ & $z^{2}$ & $\frac{\circ}{2}$ & $\mathrm{kWh} / \mathrm{yr}$ & 8 & 8 \\
\hline $\mathrm{S}$ & Two floating inlets & 70500 & 126 & 100 & 85100 & 110 & 100 \\
\hline s & $\begin{array}{l}\text { Heatexchanging coil } \\
\text { or inlet top tank }\end{array}$ & 66200 & 119 & 94 & 82700 & 107 & 97 \\
\hline $\mathrm{S}$ & Porous medium & 63800 & 114 & 91 & 81100 & 105 & 95 \\
\hline $\mathrm{S}$ & $\begin{array}{l}\text { Coil for heating } \\
\text { system }\end{array}$ & 69800 & 125 & 99 & 84700 & 109 & 100 \\
\hline U & Uniform storage & 56600 & 100 & 79 & 77900 & 100 & 91 \\
\hline
\end{tabular}

Table 1. 
Table 1 shows absolute and relative energies displaced for various system configurations at a pumping energy of $.4 \mathrm{wm}^{-2}$ for a collector flow rate of $.015 \mathrm{~m}^{3} \mathrm{~m}^{-2} \mathrm{hr} r^{-1}$. $\mathrm{S}=$ stratified storage $U=$ uniform storage. All values refer to the particular optimum operating point of the individual system.

\section{COLLECTOR- AND DISTRIBUTION CIRCUIT FLOW RATE}

One of the most striking results of the optimisation studies at the EUT was that in order to obtain a maximum heat gain the average collector flow rate in systems with a stratified storage should be roughly equal to the average flow rate in the distribution system $|5|$. From systems with an on-off control and a fixed collector flow rate the best ratio between the flow rates was found to lie between 1 and 1.5 depending on secondary circumstances (for different working fluids in the collector and distribution circuit heat capacity flow rates should be read instead of (mass) flow rates). The objective of this paper being to demonstrate that these theoretical results hold for actual systems we also transformed the results presented so far to that flow ratio: The resulting cūrves, depicted in Figure 5 clearly show the optima to lie in the region mentioned. The optimum being rather flat a rule of thumb for the pre-design stage might be that this average flow ratio should be chosen at 1.2 .

For the sake of completeness I want to add that not only the collector/distribution flow ratio, but also the storage volume (heat capacity) and the effectiveness of the heating system play a role in the position of the optimum operating point. Finally I want to point out that the very essence of the optimising of such systems can be reduced to the rule: Avoid as far as possible any temperature equalisation anywhere in the system $|6|$. 